\title{
Barriers to E-Commerce Adoption: Consumers' Perspectives from a Developing Country
}

\author{
Moudi Almousa
}

Department of Food Science and Nutrition, King Saud University, Riyadh, Saudi Arabia.

Email: almousa@ksu.edu.sa

Received March $3^{\text {rd }}, 2013$; revised May $1^{\text {st }}, 2013$; accepted June $1^{\text {st }}, 2013$

Copyright (C) 2013 Moudi Almousa. This is an open access article distributed under the Creative Commons Attribution License, which permits unrestricted use, distribution, and reproduction in any medium, provided the original work is properly cited.

\begin{abstract}
Although e-commerce has become a familiar retail channel for businesses in developed countries, it is still considered an innovation in developing countries. Specifically, electronic commerce (e-commerce) in Saudi Arabia is still in the first stage despite its advance and fast growth in ICT marketplace, the highest increase in Internet penetration in the world, strong retail sector, and young population. This research study aims to identify tangible barriers influencing consumers in Saudi Arabia to adopt e-commerce. An exploratory research design is used to shed light on the tangible barriers facing Saudi consumers when shopping online. This research study identified key tangible barriers and their relative importance for both e-commerce adapters and non-adapters facing Saudi consumer when shopping online. Practical as well as managerial implications are discussed.
\end{abstract}

Keywords: E-Commerce; Online Shopping; Barriers; Adoption; Saudi Arabia

\section{Introduction}

The Information and communication technologies (ICT) have transformed how retailers and consumers buy, distribute, and customize products. The electronic commerce (e-commerce) boom last decade along with the Internet boom in the 1990's have changed the way businesses interact with their customers. Fueled by mobile and social commerce, e-commerce is expected to be one of the important keys to the success and growth in the current competitive business environment. Although ecommerce has become a familiar retail channel for businesses in developed countries, it is still considered an innovation in developing countries. Specifically, e-commerce in Saudi Arabia is still in the first stage, despite its advance and fast growth in ICT marketplace, the highest increase in Internet penetration in the world, strong retail sector, and young population.

Saudi Arabia has the second largest Internet users (13 million) and the highest Facebook users (5.9 million) in the Middle East with $49.0 \%$ Internet penetration among the population [1]. Although the country is the largest retail market in the Middle East, online sales comprise only a small percentage of total retail sales. Saudi Arabia's Internet users spend over $\$ 3.28$ billion in $\mathrm{B} 2 \mathrm{C}$ e-commerce during 2010, with total retail sales of $\$ 77$ billion in 2010 [2]. More than forty eight percent of Internet users in Saudi Arabia reported purchasing products and services online and through their mobile handsets over the past twelve months $[3,4]$. According to Business Monitor International Report (2009) the forecast annual private consumption growth in the country is $6.0 \%$ in 2012 having been boosted by higher government spending on public-sector wages and social and unemployment benefits. The retail market in Saudi Arabia is the largest in the Middle East. It is the fourth largest sector in the country after oil, banking, and telecommunication, contributing to $17 \%$ of GDP. Despite the mentioned drivers which constitute a good platform for e-commerce adoption, using the Internet as a shopping medium has not been harness at the same speed by both retailers and consumers $[5,6]$.

Therefore, the main contribution of this study is to identify tangible barriers influencing consumers in Saudi Arabia to adopt e-commerce. An exploratory research design is used to shed light on the tangible barriers facing Saudi consumers when shopping online.

Although the area of e-commerce adoption from a consumer perspective has been wildly studied in developed countries, it is yet to be reexamined in the context of developing countries. The purpose of this research paper is to identify barriers to e-commerce adoption 
among Saudi Arabian consumers.

Finally, few expletory studies have been conducted recently that consider Internet shopping diffusion, e-commerce adoption from retailers' perspectives, an e-service adoption in Saudi Arabia. No studies have been found focusing on tangible barriers to e-commerce adoption from consumers' perspectives. This research paper attempts to fill in the gap in exploring tangible barriers to e-commerce adoption from consumer perspective in the country. The paper opens with a review of the global literature in e-commerce as well as adoption barriers from a consumer perspective and the contextual setting of e-commerce in the country, followed by a research methodology, then the findings and a conclusion.

\section{Literature Review}

The advancement in information technology and the development of Internet impact the whole society commerce and make a big change on economies. The diffusion of e-commerce in developing countries is an important economic indicator of growth due to the reduction of transaction cost [7].

\subsection{E-Commerce Barriers}

Many studies have been conducted globally to better understand challenges and drivers to e-commerce adoption from both $\mathrm{B} 2 \mathrm{~B}$ and $\mathrm{B} 2 \mathrm{C}$ domains. E-commerce adoption has been studied from both information systems and consumer behavior. In early studies regarding ecommerce adoption in developed countries, Fram and Grady (1995) [8] concluded that the most concerns for online shoppers are transaction issues such as lack of credit card security, vendors not fully identified, and a lack of payment alternatives. In addition, fear of online transaction was identified as the most significant barriers that prevent online browsers from becoming online buyers [9].

Trust has been identified in e-commerce literature as a perceived risk and a barrier to Internet adoption. Consumers with previous Internet experience have a positive attitude towards Internet shopping and place more trust on it [10]. In addition, security concerns, for both; credit card and personal information, were identified as the major barrier to Internet shopping adoption. Consumers perceive more security during online transactions if online vendors can demonstrate that their websites are secure, the consumer then, will recognize the seller's intention to provide security requirements during online transaction $[11,12]$.

In an early stage of online shopping adoption, [13] reported that consumers were most concerned about being unable to examine the product physically prior to purchase, cost of shipping, credit card security, and privacy of personal information. Similar findings were also re- ported with US consumers, where loss of privacy of personal information, after-sale services (return and exchange), being unable to examine the product prior to purchase, shipping costs, and seller anonymity are barriers to online shopping adoption [14].

Gibbs, et al. (2003) [15] conduct a cross-country comparison study including USA, Germany, France, Denmark, Brazil, Mexico, Japan, China and Singapore to examine global, environmental, and policy factors that act as determinant of e-commerce diffusion. Results of the study indicated that B2B is driven by global forces, while $\mathrm{B} 2 \mathrm{C}$ is driven by local phenomena. The study further identifies that consumer demand to purchase online, consumer purchasing power, business e-readiness, strong ICT infrastructure, and government promotion act as enablers for B2C e-commerce. Whereas payment method options, language, available shopping alternatives, lack of consumer trust, shopping channel preference, on site product information, reluctance to buy online, and inequality in socioeconomic level act as barriers to B2C e-commerce. A study conducted by OECD (2007) [16] on barriers hindering e-commerce adoption in developing countries identified some barriers, which varied widely among countries. Most identified barriers are related to infrastructure such as (network availability of ICT skills, technology, qualified human resources), cost of equipment and service, security and privacy issues, payment systems, poor distribution logistics, after-sale services, and lack of feel and touch in online shopping context. Other consumers either in developing countries or in developed countries across Europe do most cross-border online shopping, where they face different barriers. SEC (2009) report on cross-border e-commerce across European States concluded that language, cultural barriers, payment methods, delivery and after-sales support are the most important hindering factors.

\subsection{E-Commerce in Saudi Arabia}

Sacha Consulting Group (2012) reported some barriers that may affect the diffusion of e-commerce in Saudi Arabia. The barriers include preference of face-to-face business deals, using the Internet just to access data and not as a shopping channel, minimal payment method options, language, and resistance to change, fear of risk taking, weak customer service quality and after-sale support, online privacy, and postal system.

Few recent studies were conducted examining e-commerce diffusion in Saudi Arabia from retailers' perspectives [18,19], e-services adoption [20], or Internet adoption [21,22]. Alsharif (2011) conducted a study on Internet adoption on Saudi Arabia and identified some barriers facing e-commerce adoption in the country, which includes lake of government regulation, the existing mailing service infrastructure, and online payment system as the most perceived barriers followed by web- 
site language, and culture and attitude. Other consumers either in developing countries or in developed countries across Europe do most online shopping cross-border, where they face different barriers. SEC (2009) [17] report on cross-border e-commerce across European States concluded that language, cultural barriers, payment methods, delivery and after-sales support are the most important hindering factors.

Retailers in Saudi Arabia are reluctant to use the Internet as a shopping channel. Only few online stores targeting all Middle Eastern consumers were launched during the past few years such as (Souq.com, e-mall.com.sa) operating both as a retail site and as a marketplace for third party sellers. The majority of online purchases are bought from international online stores. Some international online stores responded to the increased volume of international purchases by arranging with a global e-commerce company that allows the online store to present international shoppers with product prices in the currency of their choice, a competitive international shipping cost, and the lowest possible order total

(www.macys.com).

Few studies were conducted to explore factors that inhibit retailers from adopting the Internet as a shopping channel. Some of the most important tangible barriers from retailers' perspectives include; Poor ICT infrastructure, lack of regulation for e-commerce to protect both retailers and consumers, mailing system, and lack of experience $[5,18,23,24]$. Starting 2005, Saudi postal services start delivering mail to houses after launching the Wasel service to deliver mail using smart mail boxes linked to satellite to locate home addresses using GPS. Prior to Wasel launch, mail was delivered to P O Boxes because of the lack of defined street addresses acceptable to the various delivery services. Therefore, the mailing system in the country was identified as an obstacle to e-commerce adoption in the country [6,24,25]. Despite the advancement in postal delivery, it is yet to be adopted by citizens especially in rural areas of the country. Another obstacle facing Saudi consumers when shopping from international online stores is the unavailability of international shipping in vender's site. Saudi post as well as other international carriers such as (Aramex) have responded to such need by providing subscribers to the e-shopping service a personal address in the country they shop from and then shipped directly to their local home addresses.

As the world is moving towards globalization, firms need to target markets cross-national boundaries. By doing so, firms need to understand factors affecting online shopping from the perspective of consumers of different countries. However, little empirical research has examined barriers affecting cross-border online shopping. Moreover, no empirical research has been found on barriers affecting e-commerce adoption in Saudi Arabia from a consumer perspective and specifically when shopping cross-border. Almost all online shopping in Saudi Arabia are done cross-border. No local firms wear found that sell products online to consumers. This study focuses on identifying barriers to e-commerce adoption in Saudi Arabia from consumers' perspectives.

The review of the above studies indicated that although there have been a good body of literature regarding Internet usage, online shopping, and factors influencing Internet adoption, few had focused on Saudi Arabian consumers. Moreover, no research has been found in identifying tangible barriers affecting Internet shopping adoption in Saudi Arabia from consumers' perspectives. This research study will attempt to fill the gap regarding this area of research.

\section{Methodology}

This research study was built on grounded theory following the approach of Strauss and Corbin (1990) [26] in addition to two focus group discussions to identify tangible barriers to adopt e-commerce from consumers' perspectives in the country. The study was carried out in two phases, a focus group phase and a survey phase. Initially, focus groups were formed for the purpose of identifying general perceptions of consumers with respect to e-commerce barriers. Students whom are Internet users attending the largest university in Riyadh city participated in two focus group discussions with ten participants in each group. Focus groups participants were recruited through e-mail messages sent to ninety college students. The identified barriers from both focus group discussions as well as the reviewed previous literature were examined using a five-point Likert scale, on which 1 indicates strongly disagree and 5 strongly agree. Eight main barriers were identified which includes; weak after-sale support, fear of product un-arrival, unavailability of international shipping in venders' site, web site language, unavailability of house mailing address, no previous experience regarding online purchasing, payment system (including not owning a credit card), and high shipping cost. The questionnaire has two sections. The first section includes demographic questions, while the second section includes statements regarding barriers related to online shopping which was identified through previous literature as well as focus groups discussion.

A web-based survey was used to collect data, which is suitable for this study because it could reach a wide audience across the country anytime and anywhere and to include only Internet users. The survey web site was advertised through e-mail messages to Saudi consumers, and was administered from February until April 2012. Prior to posting the questionnaire online, it was pretested with a group of thirteen college students to test for clarity and accuracy, then corrections were made accordingly. 
This research is primarily expletory in nature. Means for barriers were calculated, then a comparison of mean differences between online shoppers and none shoppers regarding identified barriers were tested using t-test.

\section{Results}

\subsection{Sample Description}

Two hundred and seventy three responses were collected. The majority of the respondents was between the ages of 18 - 35 and had a university degree. A little over half of respondents $(53 \%)$ were students and had a monthly income of less than $\$ 1000(31.1 \%)$ or financially dependent on others (33.2\%). A little over half of them have no previous experience on buying through the Internet. Percentages related to demographic characteristics of respondents are presented in Table 1.

Table 1. Demographic profile of the sample.

\begin{tabular}{|c|c|c|c|}
\hline Variable & Total & Buyers & Non buyers \\
\hline \multicolumn{4}{|l|}{ Gender } \\
\hline Male & 56.4 & 50.3 & 49.7 \\
\hline Female & 43.6 & 47.2 & 52.8 \\
\hline \multicolumn{4}{|l|}{ Age } \\
\hline Less than 18 & 2.5 & 48.9 & 51.1 \\
\hline $18-25$ & 62.1 & 37.7 & 62.3 \\
\hline $26-35$ & 21.3 & 66.7 & 33.3 \\
\hline $36-45$ & 11.0 & 71 & 29 \\
\hline Over 45 & 3.2 & 77.8 & 22.2 \\
\hline \multicolumn{4}{|l|}{ Education } \\
\hline$<$ High School & 1.1 & 33.3 & 66.7 \\
\hline High School & 20.6 & 41.4 & 58.6 \\
\hline Associate degree & 5.0 & 50 & 50 \\
\hline University degree & 62.1 & 48.6 & 51.4 \\
\hline Graduate degree & 11.3 & 65.6 & 34.4 \\
\hline \multicolumn{4}{|l|}{ Job designation } \\
\hline Government & 18.8 & 56.6 & 43.4 \\
\hline Private sector & 17.4 & 79.6 & 20.4 \\
\hline Business & 1.1 & 100 & 0 \\
\hline Student & 53.2 & 51.9 & 48.1 \\
\hline Do not work & 9.6 & 34.7 & 56.3 \\
\hline \multicolumn{4}{|l|}{ Monthly income } \\
\hline Less than $\$ 1000$ & 31.2 & 38.6 & 61.4 \\
\hline$\$ 1000-\$ 1600$ & 5.3 & 53.3 & 46.7 \\
\hline$\$ 1601-\$ 2200$ & 3.2 & 55.6 & 44.4 \\
\hline$\$ 2201-\$ 3000$ & 5.0 & 64.3 & 35.7 \\
\hline$\$ 3000-\$ 4000$ & 5.3 & 60 & 40 \\
\hline Over $\$ 4000$ & 16.7 & 78.7 & 21.3 \\
\hline Dependent & 33.3 & 38.3 & 61.7 \\
\hline \multicolumn{4}{|l|}{ Marital Status } \\
\hline Married & 31.9 & 38 & 62 \\
\hline Unmarried & 68.1 & 72.2 & 27.8 \\
\hline \multicolumn{4}{|l|}{ Internet purchase } \\
\hline Yes & 48.9 & & \\
\hline No & 51.1 & & \\
\hline
\end{tabular}

Table 2 reports the means and standard deviations for barriers affecting e-commerce adoption for the study sample. Results showed that weak after-sale support has the highest mean $(\mathrm{M}=3.55$, sd. $=1.36)$ while not having a home mailing address has the lowest mean score among barriers $(\mathrm{M}=2.32$, sd. $=1.48)$. Figure 1 illustrates the same information with barriers being ranked according to its mean score starting from the highest to the lowest mean score.

Table 3 and Figure 2 present means and standard deviation for both adapters and non-adapters with regard to barriers to e-commerce adoption in Saudi Arabia.

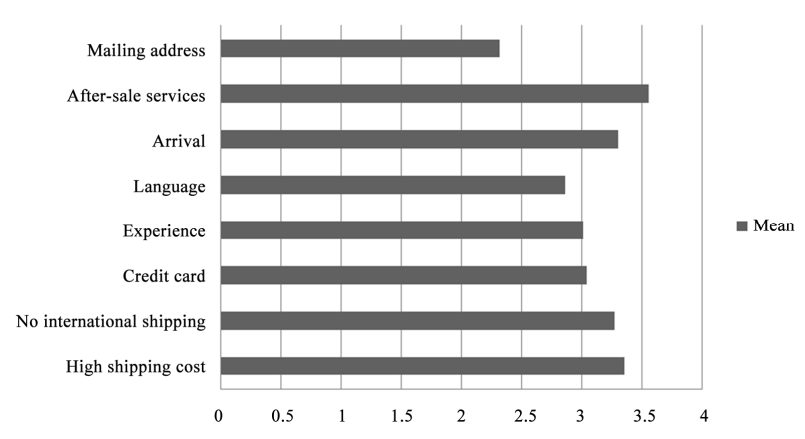

Figure 1. Barrier means for total respondents.

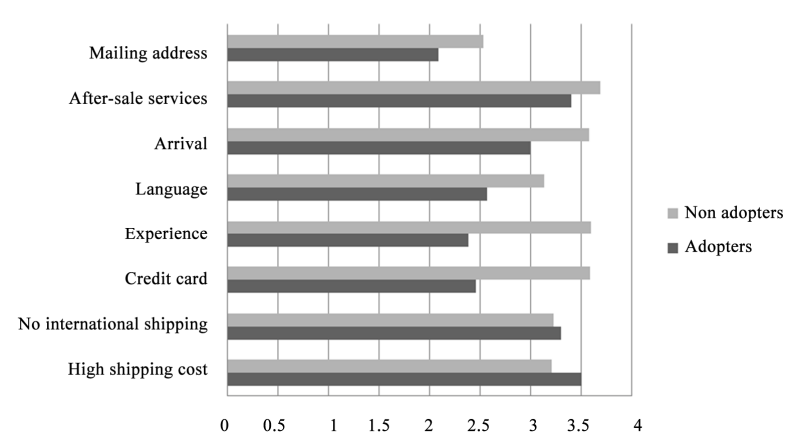

Figure 2. Mean differences between adapters and nonadapters.

Table 2. Mean and standard deviation of the perceived barriers.

\begin{tabular}{lcc}
\hline Barriers & Mean & SD \\
\hline High shipping cost & 3.35 & 1.206 \\
No international shipping & 3.27 & 1.228 \\
Credit card & 3.04 & 1.686 \\
Experience & 3.01 & 1.513 \\
Language & 2.86 & 1.457 \\
Arrival & 3.30 & 1.415 \\
After-sale services & 3.55 & 1.368 \\
Mailing address & 2.32 & 1.487 \\
\hline
\end{tabular}


Table 3. Means and standard deviation for adopters and non-adopters.

\begin{tabular}{lcccc}
\hline \multirow{2}{*}{ Barrier } & \multicolumn{2}{c}{ (133) Adopters } & \multicolumn{2}{c}{ (140) Non Adopters } \\
\cline { 2 - 5 } & $\mathrm{M}$ & $\mathrm{SD}$ & $\mathrm{M}$ & $\mathrm{SD}$ \\
\hline High shipping cost & 3.51 & 1.222 & 3.21 & 1.176 \\
No international & 3.31 & 1.295 & 3.23 & 1.163 \\
shipping & 2.46 & 1.657 & 3.59 & 1.526 \\
Credit card & 2.39 & 1.411 & 3.60 & 1.365 \\
Experience & 2.57 & 1.480 & 3.14 & 1.382 \\
Language & 3.00 & 1.404 & 3.58 & 1.372 \\
Arrival & 3.41 & 1.402 & 3.69 & 1.324 \\
After-sale services & 2.09 & 1.385 & 2.54 & 1.550 \\
Mailing address & & & & \\
\hline
\end{tabular}

Results indicated that non-adapters showed higher means regarding seven of the nine tested barriers which includes; being not able to touch or inspect the product $(\mathrm{M}=3.13$, sd. $=1.24)$, not owning a credit card $(\mathrm{M}=$ 3.59 , sd. = 1.52$)$, lake of previous experience in online purchasing $(\mathrm{M}=3.60$, sd. $=1.36)$, web site language $(\mathrm{M}$ $=3.14$, sd. $=1.38)$, fear of product un-arrival $(\mathrm{M}=3.58$, sd. $=1.37)$, weak after-sale support $(\mathrm{M}=3.69$, sd. $=$ 1.32), and not having a home mailing address $(\mathrm{M}=2.54$, sd. $=1.55$ ), while adapters showed higher mean scores in tow barriers including; high shipping cost $(\mathrm{M}=3.51$, sd. $=1.22$ ) and unavailability of international shipping in vendors site $(\mathrm{M}=3.31$, sd. = 1.29). Weak after-sale support was perceived by non-adapters as the highest barrier $(\mathrm{M}=3.69$, sd. $=1.32)$ followed by not having a previous experience in online purchasing $(\mathrm{M}=3.60$, sd. $=1.36)$, not owning a credit card $(\mathrm{M}=3.59$, sd. $=1.52)$, and fear of product un-arrival $(\mathrm{M}=3.58$, sd. $=1.37)$, while not having a home mailing address was perceived by non-adapters as the lowest barrier $(\mathrm{M}=2.54$, sd. $=1.55)$. Adapters differ in evaluating barriers, where high international shipping cost was perceives as the highest barrier $(\mathrm{M}=3.51$, sd. $=3.51)$ followed by weak after-sale support $(\mathrm{M}=3.41$, sd. $=1.40)$, unavailability of international shipping in vendors site $(\mathrm{M}=3.31$, sd. $=1.29)$, while not having a home mailing address was also perceived by adapters as the lowest barrier.

T-test was performed to examine wither the obtained barrier mean scores differ significantly between e-commerce adapters and non-adapters. Results of the t-test indicated that they differ significantly in seven of the identified barriers, while no significant difference were found between adapters and non-adapters regarding unavailability of international shipping in vendors site and weak after-sale support Table 4.

\section{Discussion, Implications and Future Research}

This research paper presents preliminary findings re-
Table 4. Mean differences between adapters and nonadapters.

\begin{tabular}{lcc}
\hline Barriers & $\mathrm{t}$ & Sig. (2 tailed) \\
\hline High shipping cost & 2.09 & 0.037 \\
No international shipping & 0.56 & 0.574 \\
Credit card & -5.94 & 0.000 \\
Experience & -7.33 & 0.000 \\
Language & -3.36 & 0.001 \\
Arrival & -3.52 & 0.000 \\
After-sale services & -1.77 & 0.076 \\
Mailing address & -2.59 & 0.010 \\
\hline
\end{tabular}

garding barriers to e-commerce adoption in Saudi Arabia from a consumer perspective. It identifies and explores barriers influencing Saudi consumers when shopping online from local or cross-border e-tailers. It can be seen that the most serious barriers facing consumers when shopping online are weak or no after-sale support, followed by high international shipping cost, then fear of product un-arrival. It is obvious that these barriers are associated with cross-border online shopping.

The most relevant practical implications of this paper can be drawn from both, the most important barriers facing e-commerce adapters and non-adapters. E-commerce adapters based on their previous experience identify the most important barriers as high international shipping cost, followed by weak or unavailability of after-sale support, then unavailability of international shipping on venders' site. Such results seem relevant with barriers identified earlier by focus group respondents before questionnaire development. While non-adapters identified the most important barriers as weak or unavailability of after-sale support, followed by lack of previous experience, then gateway payment system specifically credit card ownership as-well-as fear of product un-arrival. Unavailability of residential postal address and website language appear to be the least significant barriers for both adapters and non-adapters. As indicated in the review of literature, language and postal system were identified as major barriers. It appears that these two barriers are no longer significant for Saudi consumers since most online shoppers are educated and English language-which the most used language in online shopping websites- is no longer a major barrier. Moreover, it also appears that the launch of Wasel by Saudi post in 2005 have encouraged consumers to subscribe to its delivery services. On the other hand, it appears that the launch of Wasel A'alami in 2009 as well as providing local private mailing address in countries were Saudi consumers shop were not adopted by many consumer since unavailability 
of international shipping in vendors site was the third most important barrier facing adapters. This might be also related to the additional cost consumers pay to carriers to ship products from provided local mailing addresses to their residential addresses, where high international shipping cost were identified by adapters as the highest barrier.

Saudi government should pay attention to factors affecting local retailers to adopt e-commerce in the country since most barriers facing consumers are associated with cross-border online shopping. Saudi government has taken large steps in enforcement and implementation of e-government among public sectors. Though, very limited efforts were done regarding e-commerce adoption for both retailers and consumers. Since e-government and e-commerce are effectively two sides of the same coin, the government role in implementing e-government should have significant implications in e-commerce adoption if more attention were paid in enforcing factors supporting its development through enactment of laws and regulations to regulate business behavior in relationship to online transactions. It appears that pervious literatures regarding barriers to e-commerce diffusion in the country from both retailers' and consumers' perspectives are related mainly to the lack of such regulations. Barriers identified in this study are mostly associated with purchasing from international retailer due to the very limited availability of local etailers. A competitive advantage can be gained by implementing such jurisdictions to assist in driving e-commerce growth in the country in order to gain, retain and grow this young, techsavvy, online shopper demographic.

Future research should be carried out to extend the knowledge regarding e-commerce adoption and diffusion in the country from both consumers and retailers perspectives. Research should concentrate in identifying urgent needed market regulation to be implemented by government as a policy maker. The question needed to be answered is why the government did not facilitate the regulatory infrastructure needed to promote e-commerce growth in the country inline with the physical infrastructure created to support e-government? Following such direction would promote e-commerce diffusion which can contribute in economic growth in both the public and private sectors.

\section{REFERENCES}

[1] Internet World Stat, "Internet Usage in the Middle East," 2012. http://www.Internetworldstats.com/stats5.htm

[2] The Arab Advisors Group, "Press Release Riyadh, Saudi Arabia," 14 July 2009.

http://www.middleeastevents.com/site/pres_dtls.asp?pid= 7195
[3] Business Monitor International (BMI), "Research and Markets," 20 July 2009.

http://www.researchandmarkets.com/reports/1057968/

[4] M. Almousa, "Profiling E-buyers in Saudi Arabia: Demographic, Experiential, and Attitudinal Factors," CrossCultural Communication, Vol. 7, No. 2, 2011, pp. 92100.

[5] S. Alfuraih, "E-Commerce and E-Commerce Fraud in Saudi Arabia: A Case Study," IEEE, 2nd International Conference on Information Security and Assurance, Busan, 24-26 April 2008, pp. 176-180.

[6] Sacha Consulting Group, "E-Commerce in Saudi Arabia: Driving the Evolution, Adoption and Growth of E-Commerce in the Retail Industry," Dubai, London, 2012.

[7] A. Molla and P. S. Licker "E-Commerce Adoption: An Empirical Investigation in a Developing Country," International Journal of Electronic Commerce, 2005.

[8] E. H. Fram and D. B. Grady, "Internet Buyers: Will the Surfers Become Buyers?" Direct Marketing, Vol. 58, No. 6, 1995, pp. 63-65.

[9] N. K. Then and M. DeLong, "Apparel Shopping on the Web," Journal of Family and Consumer Sciences, Vol. 91, No. 3, 1999, pp. 65-68.

[10] N. Donthu and A. Garcia, "The Internet Shopper," Journal of Advertising Research, Vol. 39, No. 3, 1999, pp. 52-58.

[11] P. A. Pavlou, "What Drives Electronic Commerce? A Theory of Planned Behavior Perspective," Academy of Management Annual Meeting, Denver, August 2002, pp. .

[12] T. Fenech and A. O'Cass, "Internet Users Adoption of Web Retailing: User and Product Dimensions," Journal of Product and brand Management, Vol. 10, No. 6, 2001, pp. 361-81. doi:10.1108/EUM0000000006207

[13] Ernst and Young, "Global Online Retailing," 2000. http://www.ey.com

[14] UCLA Centre for Communication Policy, "Surveying the Digital Future," 2003. http://www.ccp.ucla.edu

[15] J. Gibbs, K. L. Kraemer and J. Dedrick, "Environment and Policy Factors Shaping Global E-Commerce Diffusion: A Cross-Country Comparison," The Information Society, Vol. 19, No. 1, 2003, pp. 5-18. doi:10.1080/01972240309472

[16] OECD, "Regions at a Glance," 2007. http://www.oecd.org/document/61/0,3746,en 26493463 1_38690301_1_1_1_1,00.html

[17] SEC, Commission of The European Communities, "Report on Cross-Border E-Commerce in the EU," Brussels, 2009.

[18] R. AlGhamdi, S. Drew and O. Alfaraj, "Issues Influencing Saudi Customers' Decisions to Purchase from Online Retailers in the KSA: A Qualitative Analysis," European Journal of Scientific Research, Vol. 55, No. 4, 2011, p. 580.

[19] S. A. Al-Somali, R. Gholami and B. Clegg, "An Investigation into the Acceptance of Online Banking in Saudi Arabia," Technovation, Vol. 29, No. 2, 2009, pp. 130-141. doi:10.1016/j.technovation.2008.07.004 
[20] H. Siddiqui, "Investigation of Intention to Use E-Commerce in the Arab Countries: A Comparison of Self-Efficacy, Usefulness, Culture, Gender, and Socioeconomic Status in Saudi Arabia and the United Arab Emirates," PhD. Dissertation, Nova Southeastern University, Orlando, 2008.

[21] R. AlGhamdi, S. Drew and W. Al-Ghaith, "Factors Influencing Retailers in Saudi Arabia to Adoption of Online Sales Systems: A Qualitative Analysis," Electronic Journal of Information System in Developing Countries $(E J I S D C)$, in press.

[22] M. Alsharif, "E-Commerce Adoption Factors and Their Implications for E-Commerce Business Strategy in Saudi Arabia," Master Thesis, Simon Fraser University, London, 2011.

[23] A. M. Aladwani, "Key Internet Characteristics and E-
Commerce Issues in Arab Countries," Information and Management, Vol. 16, No 1, 2003, pp. 9-20.

[24] A. Al-Solbi and P. J. Mayhew, "Measuring E-Readiness Assessment in Saudi Organizations: Preliminary Results from a Survey Study," The Proceedings of the 1st European Conference on Mobile Government, Brighton, 10-12 July 2005, pp. 467-475.

[25] Saudi Post, "Saudi Post: Establishment and Development," 2009.

http://www.sp.com.sa/Arabic/SaudiPost/aboutus/Pages/es tablishmentanddevelopment.aspx

[26] A. Strauss and J. Corbin, "Basics of Qualitative Research Grounded Theory Procedures and Techniques," Sage Publications, Thousand Oaks, 1990. 